\title{
Clinical and psychosocial predictors of illness duration from randomised controlled trial of prescribing strategies for sore throat
}

\author{
P Little, C Gould, I Williamson, G Warner, M Gantley, A L Kinmonth
}

Community

Clinical Sciences

(Primary Medical

Care Group),

Faculty of Health,

Medicine and

Biological Sciences,

Aldermoor Health

Centre,

Southampton

University,

Southampton

SO16 5ST

P Little

MRC clinician

scientist

C Gould

research assistant

I Williamson

senior lecturer in

primary care

M Gantley

anthropologist

A L Kinmonth

professor of primary

medical care

Nightingale

Surgery, Romsey,

Hampshire

SO517QH

G Warner

general practitioner

Correspondence to:

P Little

psl3@soton.ac.uk

BMJ 1999;319:736-7
Sore throat is one of the commonest reasons for visiting general practitioners yet little is known about what factors are important in its natural course. This is important since people with prolonged illness after the consultation-the $36 \%$ with illness lasting more than five days after seeing the doctor (the median)-are much more likely to reattend. ${ }^{1}$ Providing patients with information about duration of illness can reduce expectation and reattendance. ${ }^{2}$ We studied factors that affect duration of sore throat and assessed whether satisfaction with the consultation independently predicts duration of illness. ${ }^{3}$

\section{Participants, methods, and results}

The methods are reported in full elsewhere. ${ }^{3}$ General practitioners documented the clinical characteristics of 716 patients presenting with sore throat, who were then randomised to one of three prescribing strategies (antibiotics, no antibiotics, delayed antibiotics). Patients recorded satisfaction with the consultation and how well their concerns had been dealt with on four point Likert scales (very, moderately, slightly, not at all) after the consultation and kept a diary of symptoms until better. Resolution of symptoms was documented by 579 patients $(81 \%){ }^{3}$. The Likert scales showed good test-retest reliability. ${ }^{3}$ In 75 consecutive attenders Likert scales on satisfaction and dealing with concerns both demonstrated criterion validity: rank correlations with previously validated scales of the medical interview satisfaction scale questionnaire ${ }^{4}$ were 0.56 and 0.58 for overall satisfaction and 0.63 and 0.61 for the distress-relief subscale.

Given that $36 \%$ of subjects had prolonged illness, we calculated that a total of 517 participants were required to have $80 \%$ power and $95 \%$ confidence to detect odds ratios of either 0.5 or 2.0 for prolonged illness with dichotomous variables with prevalences of 25\%-75\% using EPI INFO. We assessed the predictive value of variables using logistic regression models by forward selection using STATA software; variables were retained if they remained significant ( $5 \%$ level).

Older patients (over 12 years), those with longer duration of illness before consultation, those with cough, and those who were less satisfied were more likely to have prolonged course (table). Shorter duration of illness before seeing the doctor was more likely with higher temperature $\left(>37.5^{\circ} \mathrm{C}\right.$; odds ratio 3.2, $95 \%$ confidence interval 1.9 to 5.5 ) and with the presence of three out of five of a defined complex of symptoms and signs (2.5; 1.5 to 4.2$){ }^{3}$ Most people $(69 \%)$ had their concerns very well dealt with; this was a better predictor of whether patients were very satisfied (odds ratio $88.6 ; 38.4$ to 177.4 ) than whether

\begin{tabular}{|c|c|c|c|c|c|}
\hline Age $>12$ & 177/211 (84) & $251 / 366(69)$ & 2.39 (1.55 to 3.66$)$ & 2.09 (1.33 to 3.28$)$ & $10.9(0.001)$ \\
\hline Sex (female) & $143 / 211(68)$ & $222 / 368(60)$ & 1.38 (0.97 to 1.98$)$ & 1.35 (0.93 to 1.97$)$ & $2.48(0.12)$ \\
\hline Further education & $82 / 210(39)$ & 138/356 (39) & $1.01(0.71$ to 1.44$)$ & 0.77 (0.52 to 1.13$)$ & $1.79(0.18)$ \\
\hline Initial antibiotics (group $1 v$ others) & $70 / 211(33)$ & $144 / 368(39)$ & 0.77 (0.54 to 1.10$)$ & 0.85 (0.58 to 1.25$)$ & $0.69(0.40)$ \\
\hline III for $>3$ days before consultation & $98 / 209(47)$ & 119/363 (33) & 1.81 (1.28 to 2.57$)$ & 1.51 (1.04 to 2.18$)$ & $4.75(0.03)$ \\
\hline Pharyngitis & 135/211 (64) & $239 / 368(65)$ & 0.96 (0.67 to 1.37$)$ & 0.89 (0.61 to 1.29$)$ & $0.38(0.54)$ \\
\hline Purulent tonsils & $32 / 211(15)$ & $62 / 368(17)$ & $0.88(0.55$ to 1.40$)$ & 0.96 (0.59 to 1.57$)$ & $0.03(0.87)$ \\
\hline Cervical glands & 101/211 (48) & $208 / 368(57)$ & 0.71 (0.50 to 0.99$)$ & 0.86 (0.60 to 1.25$)$ & $0.60(0.44)$ \\
\hline Temperature $>37.5^{\circ} \mathrm{C}$ & $22 / 149(15)$ & $76 / 280(27)$ & $0.46(0.28$ to 0.78$)$ & 0.58 (0.33 to 1.03$)$ & $3.57(0.06)$ \\
\hline $3 / 5$ of symptom complex $†$ & $25 / 143(17)$ & $69 / 269(26)$ & 0.61 (0.37 to 1.02$)$ & 0.90 (0.49 to 1.66$)$ & $0.12(0.73)$ \\
\hline \multicolumn{6}{|l|}{ Psychosocial } \\
\hline \multicolumn{6}{|l|}{ Satisfaction with consultation: } \\
\hline Very satisfied & 131/206 (64) & $269 / 363(74)$ & $1.00 \ddagger$ & $1.00 \Uparrow$ & $7.05(0.008)$ \\
\hline Moderately & $56 / 206(27)$ & 78/363 (21) & $1.47(0.98$ to 2.20$)$ & $1.39(0.92$ to 2.1$)$ & \\
\hline Slightly & $12 / 206(6)$ & $12 / 363(3)$ & 2.05 (0.89 to 4.68$)$ & $2.10(0.90$ to 4.90$)$ & \\
\hline Not at all satisfied & $7 / 206(3)$ & $5 / 363(1)$ & $2.87(0.89$ to 9.20$)$ & $2.86(0.87$ to 9.41$)$ & \\
\hline $\begin{array}{l}\text { Legitimation for work or school very or } \\
\text { moderately important }{ }^{3}\end{array}$ & $123 / 205(60)$ & $218 / 361(60)$ & 1.01 (0.71 to 1.44$)$ & 1.03 (0.72 to 1.49$)$ & $0.03(0.87)$ \\
\hline
\end{tabular}


an antibiotic was prescribed $(2.97 ; 1.54$ to 5.74$)$. Satisfaction was not predicted by any other variable.

\section{Comment}

This trial excluded very ill patients but should inform advice to most patients. Selection and non-response bias were not significant ${ }^{3}$ so despite limitations, these data are likely to provide generalisable estimates of the predictors of duration of illness.

Patients over 12 and those with cough were more likely, and those with shorter illness before consultation less likely, to have prolonged illness. Short duration before consultation was associated with higher temperature and presence of three out of five symptoms and signs. Thus patients with a higher temperature are more likely to present sooner but also get better more quickly.

Satisfaction with the consultation predicted duration of illness independently of potential confounding variables and was more closely related to effective doctor-patient communication than to prescription of antibiotics. This supports both the preliminary analysis $^{3}$ and evidence from a systematic review. ${ }^{5}$ Doctors should elicit patients' concerns and consider counselling patients-particularly those at risk of prolonged illness-about the natural course of sore throat.
We thank the following general practitioners for their help in recruitment, constructive comments, and enthusiasm: Nigel Dickson, Graham Newman, Peter Willicombe, Peter White, Sue Tippett, Richard Peace, Julie Chinn, Katie Warner, Neil Ball, Tim Taylor, Deidre Durrant, Mark Rickenbach, Sally Bacon, Tim Whelan, Peter Markby, Simon Goodison, D Traynor, R Briggs, Evelyn Beale, Fiona Bradley, Simon Smith, and Stephen Morgan.

Contributors: PL had the original idea for the study. The protocol was developed by all the authors. Data collection, day to day study management, data entry, and data cleaning were managed by CG. Analysis was performed by PL, and all authors contributed to writing the paper. PL is the guarantor.

Funding: This work was supported by Wessex NHS Regional Research and Development funds. PL is currently supported by the MRC, but during the data collection for this study was supported by the Wellcome Trust.

Competing interests: None declared.

1 Little PS, Gould C, Williamson I, Warner G, Gantley M, Kinmonth AL. Reattendance and complications in a randomised trial of prescribing strategies for sore throat: the medicalising effect of prescribing antibiotics. BMJ 1997:315:350-2.

2 Macfarlane JT, Holmes WF, Macfarlane RM, Lewis S. Reducing reconsultation for acute lower respiratory tract illness with an information leaflet: a randomised controlled study of patients in primary care. Br J Gen Pract $1997 ; 47: 719-22$.

3 Little PS, Williamson I, Warner G, Gould C, Gantley M, Kinmonth AL. An open randomised trial of prescribing strategies for sore throat. $B M$ J $1997 \cdot 314 \cdot 792-7$

4 Wilkin D, Hallam L, Doggett AM. Measures of need and outcome for primar health care. Oxford: Oxford University Press, 1992.

5 Stewart M. Effective physician-patient communication and health outcomes: a review. Can Med Assoc J 1995;152:1423-33.

(Accepted 29 June 1999)

\section{A dilemma Entering the minds of the elderly}

I was sorting things out pretty well. They had been attending for only a few weeks, but I had managed to reduce their multiple drug regimens and to diagnose and control his atrial fibrillation. Bill and Netty were a delightful couple, always attending together and obviously devoted to one another. Their delight in their new sheltered house and enjoyment of their new town was a pleasure to see.

Now I raised the question of Bill's microscopic haematuria, discovered at the registration medical and present on further samples. "Probably due to your prostatectomy five years ago," I said, "but I'd advise a check at the hospital just to be sure." He seemed hesitant. "It's a small operation-you'll be in and out in a day," I reassured and went on to outline the procedure. Netty beamed her approval. "Well, if you're quite sure, Doctor," Bill said uncertainly. I felt clever and kind.

At cystoscopy no cause of haematuria was found, but a large bladder diverticulum (with suspicious ultrasound echo) could not be visualised. Problems developed a few days later. He developed a urinary infection, acute retention, and renal failure and required urgent admission to hospital. A niece took Netty to her home at which point the extent of her dementia became apparent. The niece was unable to cope with the agitation and the wandering. A few days later, Netty too required admission to hospital, and the unhappy scenario was complete-Bill and Netty separated and both in hospital. As the instigator of this disaster I felt foolish and cruel.

What had gone wrong? I had failed to recognise Netty's dementia and her complete dependence on Bill. Their attendance always together was the clue I had missed. But missing this would not have been disastrous had I sought to involve Bill in the decision to refer him for cystoscopy. Had I done this, he would surely have indicated his concerns and communicated his priorities. I had not stopped to consider that there might be a priority of maintaining their joint independence which far outweighed the need to diagnose urological cancer in an asymptomatic 85 year old.

Fortunately, all was not lost. The holistic and non-elaborate care of the community hospital came to the rescue and allowed their eventual joint discharge home. Bill now shared his view that he would not contemplate further investigation while his overwhelming priority was to keep Netty at home with him for as long as possible. He would take the risk of undiagnosed advancing cancer.

For a further six months he continued to achieve his aim of caring for Netty. Then he ran into further trouble with renal failure caused by obstructive uropathy. He died a few days after readmission. A large fungating bladder tumour was found at necropsy.

Communicating with the elderly is a difficult skill. All sorts of factors get in the way, not least a paternalistic approach, often misguided, sometimes disastrous. Perhaps even more than with younger patients, we need to find time to seek the ideas and concerns of elderly people if we are to meet their needs adequately and sensitively. The priorities of the elderly can be surprisingly different from those of younger patients. The need to preserve and not to put at risk personal or coupled autonomy is sometimes of paramount concern.

Malcolm Lindsay, general practitioner, Galashiels

We welcome articles up to 600 words on topics such as A memorable patient, A paper that changed my practice, My most unfortunate mistake, or any other piece conveying instruction, pathos, or humour. If possible the article should be supplied on a disk. Permission is needed from the patient or a relative if an identifiable patient is referred to. We also welcome contributions for "Endpieces," consisting of quotations of up to 80 words (but most are considerably shorter) from any source, ancient or modern, which have appealed to the reader. 